Original Article

\title{
Comparison of Gait Aspects According to FES Stimulation Position Applied to Stroke Patients
}

\author{
ByeOng-Mu Mun, PT, MSc ${ }^{1)}$, TAe-Ho Kim, PT, PhD ${ }^{2 *}$, Jin-HWAn Lee, PT, MSc ${ }^{1)}$, \\ Jin-Youg Lim, PT, MSc'1), Dong-Kwon Seo, PT, MSc ${ }^{3)}$, Dong-Jin Lee, PT, $\mathrm{PhD}^{4)}$ \\ 1) Department of Rehabilitation Science, Graduate School, Daegu University, Republic of Korea \\ 2) Department of Physical Therapy, College of Rehabilitation Sciences, Daegu University: 201 \\ Daegudae-ro, Jillyang, Gyeongsan, Gyeongbuk, Republic of Korea \\ 3) Department of Physical Therapy, Konyang University, Republic of Korea \\ 4) Department of Physical Therapy, Gwangju Health University, Republic of Korea
}

\begin{abstract}
Purpose] This study sought to identify the gait aspects according to the FES stimulation position in stroke patients during gait training. [Subjects and Methods] To perform gait analysis, ten stroke patients were grouped based on 4 types of gait conditions: gait without FES stimulation (non-FES), gait with FES stimulation on the tibialis anterior (Ta), gait with FES stimulation on the tibialis anterior and quadriceps (TaQ), and gait with FES stimulation on the tibialis anterior and gluteus medius (TaGm). [Results] Based on repeated measures analysis of variance of measurements of gait aspects comprised of gait speed, gait cycle, and step length according to the FES stimulation position, the FES stimulation significantly affected gait aspects. [Conclusion] In conclusion, stimulating the tibialis anterior and quadriceps and stimulating the tibialis anterior and gluteus medius are much more effective than stimulating only the tibialis anterior during gait training in stroke patients using FES.

Key words: Stroke, FES, Gait
\end{abstract}

(This article was submitted Sep 26, 2013, and was accepted Nov. 4, 2013)

\section{INTRODUCTION}

Gait disability among stroke patients is a very common symptom that is observed in $80 \%$ of all patients. Thisdisability is attributed to damage due to the lesions associated with the unification function of the higher cortical and kinesthesis tract. It appears as a result of direct damage, non-activity occurring secondarily, or by non-use ${ }^{1)}$. The gait aspects of stroke patients manifest with a wide variety of patterns ${ }^{2}$.Generally, slow excessive force and effort are required, and coordination does not work properly. In addition, large-scale movements are noted ${ }^{1,3)}$.

Functional electrical stimulation (FES) is recently being used to establish a normal gait pattern among stroke patients. Therapeutic intervention with FES can enhance the control ability of a paretic limb within cooperative movements due to intensive enhancement of muscular strength ${ }^{4)}$. Moreover, functional electrical stimulation on a residual nerve conduction tract after damage can improve the lost exercise ability of patients ${ }^{5}$ and can help maximize relearning of a sports activity for patients during active and repetitive movements ${ }^{6,7)}$.

*Corresponding author. Tae-ho Kim (E-mail: ptkimth@ daegu.ac.kr)

C 2014 The Society of Physical Therapy Science. Published by IPEC Inc. This is an open-access article distributed under the terms of the Creative Commons Attribution Non-Commercial No Derivatives (by-ncnd) License $<$ http://creativecommons.org/licenses/by-nc-nd/3.0/> .
In advanced research regarding gait training through FES, FES applied to a sural nerve prevents foot drop by recovering the dorsiflexion muscle at the swing phase. It is effective in increasing gait speed by decreasing the spasticity of the plantar flexion muscle ${ }^{8)}$. Lee et al. ${ }^{9)}$ stated that functional electrical stimulation on the gluteus medius contributes to a patient's daily range of motion and to independent gait by enhancing gait ability in hemiplegic stroke patients. Furthermore, Bogataj et al. ${ }^{10)}$ reported that treatment with electrical stimulation using a surface electrode during the acute period of stroke shows a faster effect on gait speed or coordination capability of a limb than other treatment methods. The study of $\mathrm{Ng}$ et al. ${ }^{11)}$ also reported that electromechanical gait training combined with FES is more effective than general physical therapy.

Thus, changes in gait after FES application have been observed in many studies, but most studies have involved an individual muscle, and not many studies have focused on the FES stimulation position. This study aimed to examine gait aspects according to the FES stimulation position in an effort to enhance gait training in stroke patients who received FES effectively during clinical treatment.

\section{SUBJECTS AND METHODS}

\section{Subjects}

The study was conducted with 10 patients whose onset of stroke was more than 6 months previously and who had undergone hospital treatment from July 29 to August 9, 
Table 1. Effects of the FES stimulation position on gait speed, gait cycle, and step length

\begin{tabular}{|c|c|c|c|c|c|c|}
\hline & & Non-FES & $\mathrm{Ta}$ & $\mathrm{TaQ}$ & $\mathrm{TaGm}$ & Post hoc \\
\hline \multicolumn{2}{|l|}{ Gait speed (m/s) } & $0.47 \pm 0.13$ & $0.53 \pm 0.15$ & $0.61 \pm 0.16$ & $0.59 \pm 0.16^{* \dagger}$ & $\mathrm{a}<\mathrm{b}<\mathrm{c}>\mathrm{d}$ \\
\hline \multicolumn{2}{|c|}{ Gait cycle (cycle/s) } & $0.61 \pm 0.13$ & $0.66 \pm 0.13$ & $0.69 \pm 0.13$ & $0.69 \pm 0.13^{* \dagger}$ & $\mathrm{a}<\mathrm{b}<\mathrm{c}=\mathrm{d}$ \\
\hline \multirow{2}{*}{ Step length $(\mathrm{cm})$} & $\mathrm{P}$ & $42.50 \pm 8.08$ & $45.20 \pm 8.63$ & $50.70 \pm 6.99$ & $48.60 \pm 6.99 * \dagger$ & $\mathrm{a}<\mathrm{b}<\mathrm{c}>\mathrm{d}$ \\
\hline & NP & $43.00 \pm 7.87$ & $45.60 \pm 8.51$ & $48.80 \pm 8.61$ & $47.60 \pm 8.24 * \dagger$ & $\mathrm{a}<\mathrm{b}<\mathrm{c}=\mathrm{d}$ \\
\hline
\end{tabular}

Mean \pm SD. Within-subjects effects: $*, p<0.05$. Between-subject effects: $\dagger, \mathrm{p}<0.05$. P, paretic side; NP, nonparetic side; non-FES, non-FES stimulation; Ta, FES stimulation on the tibialis anterior muscle; TaQ, FES stimulation on the tibialis anterior and quadriceps muscle; TaGm, FES stimulation on the tibialis anterior and gluteus medius muscle

2013, at D hospital located in Jeonju, Republic of Korea. The subjects could perform independent gait and had sufficient passive ranges of motion of ankle dorsiflexion that enabled the paretic ankle joint to reach either the neutral ankle angle $\left(0^{\circ}\right)$ or a minimum of $5^{\circ}$ of plantar flexion with the knee flexed. Patients who had respiratory, cardiovascular, or orthopedic diseases were excluded from the study. All subjects understood the purpose of the study and gave written consents before participating, according to the ethical standards of the Declaration of Helsinki.

\section{Methods}

In this study, test conditions were divided into gait without FES stimulation (non-FES), gait with FES stimulation on the tibialis anterior (Ta), gait with FES stimulation on the tibialis anterior and quadriceps $(\mathrm{TaQ})$, and gait with FES stimulation on the tibialis anterior and gluteus medius (TaGm)in order to evaluate gait aspects according to the FES stimulation position. Subjects slowly walked three round trips of $20 \mathrm{~m}$ and performed a free gait three times for a total of 20 minutes so that they could become accustomed to the changes brought about by the FES application. Gait training was not performed on the day the measurements were taken. Subjects were subjected to all 4 conditions, and gait analysis was performed for each. The order for applying the conditions was random, and a five-minute break was provided in between measurements.

In this study, a gait analysis training treadmill, Gait Trainer 2 (Biodex Medical Systems, Shirley, NY, USA, 2010), was used to examine gait speed, gait cycle, and step length, which are general components of gait. Patients were allowed to adjust the gait speed for safety and comfort considerations, and were given 3 minutes to get used to the machine. Their measurements were taken for 1 minute. Walking Man II (CyberMedic Corp., Iksan, Korea, 2010) was used for FES.

A foot switch was attached to the heel for FES so that the quadriceps and gluteus medius were stimulated when the heel come into contact with the treadmill and the tibialis anterior was stimulated when the heel lifted off the treadmill. The parameters of FES stimulation were symmetrical biphasic square waves with a pulse width of $250 \mu \mathrm{s}$, while the frequency was $40 \mathrm{~Hz}$. The intensity of stimulation was set just enough for the naked eye to observe contractions of the muscle.

Statistical analysis was conducted using SPSS 18.0 for
Windows. To evaluate gait aspects according to the FES stimulation position, statistical analysis with repeated measures was performed, and the LSD test was used for post hoc analysis. The significance level was set to $\mathrm{p}<0.05$ for the statistical analysis.

\section{RESULTS}

This study was conducted with 10 subjects who were tested with FES stimulation under each of the 4 conditions identified. The general characteristics of the subjects were as follows: age, $47.80 \pm 8.37$ years; height, $166.00 \pm 6.64 \mathrm{~cm}$; weight, $65.90 \pm 5.91 \mathrm{~kg}$; onset, $18.90 \pm 10.90$; gender, male 7 and 3 female; diagnosis, 7 cases of hemorrhage and 3 cases of infarction; and Fugl-Meyer Assessment scale, 23.70 \pm 4.42 (lower extremity motor assessment test and balance test).

In order to examine the effects of the FES stimulation position on gait components, gait speed, gait cycle, and step length among the general measurement elements were measured. Step length was measured separately on the paralyzed and non-paralyzed sides. There was a statistically significant difference in gait aspects as a result of FES stimulation depending on gait speed, gait cycle, and step length (paralyzed/non-paralyzed). The post-analysis results showed that walking with the following stimulation procedures was most effective for each element: FES stimulation on the tibialis anterior and quadriceps was most effective for gait speed, FES stimulation on the tibialis anterior and quadriceps as well as FES stimulation on the tibialis anterior and gluteus medius was most effective for gait cycle, and FES stimulation of the tibialis anterior and quadriceps on the paralyzed side and FES stimulation on the tibialis anterior and quadriceps as well as FES stimulation on the tibialis anterior and gluteus medius on the non-paralyzed side were most effective for step length (Table 1).

\section{DISCUSSION}

Among many studies aimed at improving the gait speed of stroke patients, the results of an meta-analysis of studies using FES revealed that FES is effective for enhancing gait speed ${ }^{12)}$. Based on the results of previous research, this study was conducted to examine the effect of the FES stimulation position on gait with the objective of finding the most effective stimulation position.

A study on FES stimulation and gait speed reported that functional electrical stimulation applied to the tibialis ante- 
rior was effective in enhancing gait speed and cadence ${ }^{13)}$. In a study on FES stimulation on the tibialis anterior, peroneus longus, quadriceps, and hamstring, effective movement of the knee joint of a paralyzed limb brought about by increased muscular strength and cross-sectional area of the muscle directly increased gait efficiency and gait speed ${ }^{14)}$ Kim et al. ${ }^{15)}$ stated that recovering the muscular strength of the hip joint abductor stabilizes the position of the hip joint, while control of the hip joint abductor is a significant element for independent gait and balance recovery; in particular, they found that the ankle dorsiflexion muscle and hip joint abductor affect gait speed ${ }^{16}$. In another study, a change in limb muscular strength reduced the dragging of the foot in the swing phase, decreasing the duration of flight of a paralyzed limb ${ }^{17}$, while gait speed increased because balance was improved due to easy movement of weight to the paralyzed side through recovery of the strength of the gluteus medius ${ }^{18)}$. FES stimulation on the dorsiflexion muscle of an ankle shortens the swing phase of a paralyzed limb and increases gait speed, while FES stimulation on the quadriceps and gluteus medius leads to increased muscular strength and effective movement of joints. This in turn brings about an increased gait speed and gait cycle, which is consistent with the results of this study.

In a study on FES stimulation, balance, and confidence, Robertson et al. ${ }^{19)}$ performed balance training with 15 stroke patients for 4 weeks by applying functional electrical stimulation on the dorsiflexion muscle and assessing the ABC (Activities-specific Balance Confidence Scale). The results showed that the test group that received functional electrical stimulation exhibited significant improvements. Also, $\mathrm{Ng}$ et al. ${ }^{11)}$ and Yang et al. ${ }^{14)}$ reported in their studies that FES stimulation increased muscular strength and improved balance ability. Recovery of the muscular strength of the gluteus medius enhances balance as movement of weight to the paralyzed side becomes easier ${ }^{18)}$, while recovery of muscular strength of the hip joint abductor acts as it's stabilizer when weight is moved. This affects the recovery of dynamic balance among stroke patients ${ }^{20)}$. Kim et al. ${ }^{21)}$ performed cross-sectional research on gait with FES on the gluteus medius and tibialis anterior and found that the step length of gait with FES on the gluteus medius and tibialis anterior showed a more significant increase than the step length of gait with FES on the tibialis anterior only or the step length of normal gait. The step length of gait with functional electrical stimulation on the tibialis anterior showed a more significant increase than the step length of normal gait. FES increases muscular strength and balance ability, increasing stability in the stance phase and increasing the step length of the opposite limb. This is consistent with the result of the present study, which showed that step length was increased more when the tibialis anterior was stimulated at the same time as the quadriceps or gluteus medius than when only the tibialis anterior was stimulated. In this study, the non-paralyzed side step length of gait with FES on the tibialis anterior and quadriceps showed a more significant increase than the step length of gait with FES on the tibialis anterior and gluteus medius. The increased step length of the non-paralyzed limb was associated with an increase in gait speed. It is considered that the regulation ability of the quadriceps exerts more influence on the gait.

Thus, FES stimulation during gait training stimulates an increase in muscular strength and effective movement of joints, increasing stability in the stance phase and step length of the non-paralyzed limb. It also stimulates dorsiflexion of the ankle in the swing phase, shortening the swing phase of the affected side and increasing the gait cycle to bring about an increasein gait speed. In clinical gait training of stroke patients, stimulating the tibialis anterior along with the quadriceps and the tibialis anterior along with the gluteus medius at the same time, instead of applying FES stimulation only on the tibialis anterior, increases limb stability and would be much more effective in recovering the gait ability of patients. The only limitation of this study is that the gait analysis was conducted on a treadmill instead of a floor surface. Future research of gait on floor surface and with a larger number of subjects that also includes balance analysis is recommended.

\section{REFERENCES}

1) Kelly J, Hunt BJ, Lewis RR, et al.: Anticoagulation or inferior vena cava filter placement for patients with primary intracerebral hemorrhage developing venous thromboembolism? Stroke, 2003, 34: 2999-3005. [Medline] [CrossRef]

2) Huitema RB, Hof AL, Mulder T, et al.: Functional recovery of gait and joint kinematics after right hemispheric stroke. Arch Phys Med Rehabil, 2004, 85: 1982-1988. [Medline] [CrossRef]

3) Caillet F, Mertens $P$, Rabaséda $S$, et al.: [Three dimensional gait analysis and controlling spastic foot on stroke patients]. Ann Readapt Med Phys, 2003, 46: 119-131. [Medline] [CrossRef]

4) Combs S, Miller EW, Forsyth E: Motor and functional outcomes of a patient post-stroke following combined activity and impairment level training. Physiother Theory Pract, 2007, 23: 219-229. [Medline] [CrossRef]

5) Thompson AK, Doran B, Stein RB: Short-term effects of functional electrical stimulation on spinal excitatory and inhibitory reflexes in ankle extensor and flexor muscles. Exp Brain Res, 2006, 170: 216-226. [Medline] [CrossRef]

6) Soetanto D, Kuo CY, Babic D: Stabilization of human standing posture using functional neuromuscular stimulation. J Biomech, 2001, 34: 15891597. [Medline] [CrossRef]

7) Chae J, Yu D: A critical review of neuromuscular electrical stimulation for treatment of motor dysfunction in hemiplegia. Assist Technol, 2000, 12: 33-49. [Medline] [CrossRef]

8) Sabut SK, Sikdar C, Kumar R, et al.: Improvement of gait \& muscle strength with functional electrical stimulation in sub-acute \& chronic stroke patients. Conf Proc IEEE Eng Med Biol Soc, 2011, 2011: 2085-2088. [Medline]

9) Lee SK, Park MC, Shim JM, et al.: The Effect of Closed Kinetic Chain Exercise with FES of the Gluteus Medius on Gait in Stroke. Korean Soc Phys Med, 2011, 6: 1-8.

10) Bogataj U, Gros N, Kljajić M, et al.: The rehabilitation of gait in patients with hemiplegia: a comparison between conventional therapy and multichannel functional electrical stimulation therapy. Phys Ther, 1995, 75: 490-502. [Medline]

11) Ng FW, Tong RK, Li LS: A pilot study of randomized clinical controlled trial of gait training in sub-acute stroke patients with partial body weight support electro mechanical gait trainer and functional electrical stimulation: six month follow up. Stoke, 2008, 39: 154-160. [Medline]

12) Robbins SM, Houghton PE, Woodbury MG, et al.: The therapeutic effect of functional and transcutaneous electric stimulation on improving gait speed in stroke patients: a meta-analysis. Arch Phys Med Rehabil, 2006, 87: 853-859. [Medline] [CrossRef]

13) Sabut SK, Sikdar C, Mondal R, et al.: Restoration of gait and motor recovery by functional electrical stimulation therapy in persons with stroke. Disabil Rehabil, 2010, 32: 1594-1603. [Medline] [CrossRef]

14) Yang CY, Kim TJ, Lee JH, et al.: The Effect of Functional Electrical Stimulation on the Motor Function of Lower Limb in Hemiplegic Patients. J Korean Acad Rehab Med, 2009, 33: 29-35. 
15) Kim CM, Eng JJ, Whittaker MW: Effects of a simple functional electric system and/or a hinged ankle-foot orthosis on walking in persons with incomplete spinal cord injury. Arch Phys Med Rehabil, 2004, 85: 1718-1723. [Medline] [CrossRef]

16) Dorsch S, Ada L, Canning CG, et al.: The strength of the ankle dorsiflexors has a significant contribution to walking speed in people who can walk independently after stroke: an observational study. Arch Phys Med Rehabil, 2012, 93: 1072-1076. [Medline] [CrossRef]

17) Lin PY, Yang YR, Cheng SJ, et al.: The relation between ankle impairments and gait velocity and symmetry in people with stroke. Arch Phys Med Rehabil, 2006, 87: 562-568. [Medline] [CrossRef]

18) Mercer VS, Chang SH, Williams CD, et al.: Effects of an exercise program to increase hip abductor muscle strength and improve lateral stability following stroke: a single subject design. J Geriatr Phys Ther, 2009, 32: 50-59. [Medline] [CrossRef]

19) Robertson JA, Eng JJ, Hung C: The effect of functional electrical stimulation on balance function and balance confidence in community-dwelling individuals with stroke. Physiother Can, 2010, 62: 114-119. [Medline] [CrossRef]

20) Gottschalk F, Kourosh S, Leveau B: The functional anatomy of tensor fasciae latae and gluteus medius and minimus. J Anat, 1989, 166: 179-189. [Medline]

21) Kim JH, Chung Y, Kim Y, et al.: Functional electrical stimulation applied to gluteus medius and tibialis anterior corresponding gait cycle for stroke. Gait Posture, 2012, 36: 65-67. [Medline] [CrossRef] 